Jahangirnagar University J. Biol. Sci. 7(1): 81-85, 2018 (June)

- Short communication

\title{
Diurnal activity pattern of white-rumped vulture, Gyps bengalensis (Gmelin, 1788) in captivity during breeding season at Bangladesh National Zoo, Dhaka
}

\author{
Md. Abraharul Islam*, Monirujjaman, Rasel Ahammed and Mahruma Aktar \\ Department of Zoology, Jahangirnagar University, Savar, Dhaka-1342, Bangladesh
}

Key words: Diurnal activity, white-rumped vulture, breeding season, captivity, Bangladesh National Zoo.

Vultures are scavenging birds of prey, play key role as a natural cleaner. Stomach acid of this bird is exceptionally corrosive, allowing them to safely digest carcasses infected with Botullinum toxin, hog cholera and anthrax bacteria that would be lethal to other scavengers and humans thus play important role in control of these diseases. Population of the white-rumped vulture Gyps bengalensis (Gmelin, 1788) and other resident species of Gyps vulture has declined very rapidly since the mid 1990s across the Subcontinent (Prakash et al., 2007; Gilbert et al., 2006). It is scientifically proven that the use of diclofenac (a nonsteroidal anti-inflammatory drug) in animals especially in cattle has led to massive mortality and a sharp decline in vulture population. Perhaps no other bird species in the world has suffered a more rapid decline than the vultures of South Asia. The bird is now critically endangered (IUCN, 2014) and facing high risk of extinction. Vulture populations in the wild are precariously small because of the low natural reproductive capacity and long duration of immaturity of vultures (even under the favorable conditions, the shortest period in which a wild vulture population can double in size is about ten years) and will remain vulnerable to adverse events until numbers have increased substantially (SAVE, 2014). The rate of the recent population decline was much more rapid than the most rapid possible rate of increase, with the population of the species most strongly affected by diclofenac halving every year (SAVE, 2014). If the rate of decline cannot be arrested, the species may disappear altogether from the Subcontinent in the next few years (Khan, 2013).

With this speed and uncertainty in mind, the precaution of taking viable numbers of this species into captivity (i.e., establishing a full-scale conservation breeding programme for future reintroduction once diclofenac had been removed) was agreed in 2004 as a key element of the Recovery Plan (IUCN, 2012; MoEF, 2006; ISARPW, 2004). The loss of tens of millions of vultures over the last decade has had major ecological consequences across the Subcontinent that pose a potential threat to human health (Swan et al., 2006).

\footnotetext{
* Corresponding author. Email: mdabraharulislam@gmail.com
} 
In current situation there is serious threat to spread of these communicable diseases to livestock and humans. Thus, it is wise to conserve vultures for human benefits. Bangladesh is considering the development of a vulture conservation breeding centre (SAVE, 2014). In this context, there is a need to understand the in-depth scientific knowledge for better management and conservation of this species.

The proper scientific knowledge on activity pattern in breeding season is the first and foremost priority for management and conservation of a wildlife species. Quantifying animal activities can identify factors that influence animal behavior (Relyea et al., 1994). Several studies on behavioral ecology of Gyps vulture were conducted in the Subcontinent. The available literature on the diurnal activity pattern of white-rumped vulture in Bangladesh is rare and imprecise. The present study was designed to know the diurnal activity pattern of white-rumped vulture in breeding season in captivity which may be useful in management practices of this species in both captivity and wild.

The study was conducted at Bangladesh National Zoo, Dhaka (23 48' 43.69" N 90 $20^{\prime}$ 40.32" E), situated in Mirpur about $16 \mathrm{~km}$ northwest from Dhaka city centre. Topographically, the Zoo area is more or less plain land with loamy and sandy soils (Ahammed et al., 2013). Rainfall and temperature patterns delimit the annual cycle into three distinct periods: hot and humid summer from March to May, monsoon from June to October, and cool and dry winter from November to February (Ahmad, 1968). The study birds were kept in an enclosure (11.5 $\times 5.5 \times 6.5 \mathrm{~m}$ approx.), consists of concrete wall, iron bars and metal mesh. It contained feed trough, freshwater tank artificial nests, perches, shade and shelter. Every day 1-1.5 kg red meat (cow) was supplied by Zoo keeper around 10.00-11.00am. The experimental birds were observed for 10 days from November 2015 to April 2016. During the intensive study, the diurnal activities were recorded at two minutes interval by using scan sampling method as described by Altmann (1974) and Martin \& Bateson (1993). Data were collected from 4 adult white-rumped vultures. The behaviour of one individual during the scan was recorded as one observation. The different activities were grouped into ten major categories viz., feeding, roosting, sleeping, walking, performing breeding activity, flying, preening, wing flapping, chasing and bathing. Special activity of vulture, which was missed in the scan sampling, was recorded as ad libitum. Activities were quantified by counting the number of events (frequency or rate measures). The frequency distribution was compared by $\chi^{2}$-test. Graphical representation was prepared by using MS-Excel software (Ver. 2007).

The observation $(n=4787)$ showed that in captivity the white-rumped vulture spent most of time of their activity budget in roosting $(56.34 \%)$ followed by preening $(10.59 \%)$, walking $(8.69 \%)$, performing breeding activity $(6.79 \%)$, wing flapping $(6.66 \%)$, flying $(4.26 \%)$, feeding $(3.03 \%)$, chasing $(2.27 \%)$, sleeping $(1.25 \%)$ and bathing $(0.12 \%)$ (Fig.1). Chi-square analysis revealed, diurnal activities were varied significantly across the ten categories $\left(\chi^{2}=11902.861, \mathrm{df}=9, \alpha=5 \%, \mathrm{p}>0.05\right)$. The highest observation $(\mathrm{n}=1698)$ was collected in November and lowest $(\mathrm{n}=199)$ was in March. Time spent in all activities showed a wide variation in different months and also in different hours of the day. Gunawan (2005) reported differences in the daily activities in captive White-bellied 
Sea Eagles Haliaeetus leucogaster. They started their diurnal activities at about 8.00$8.30 \mathrm{am}$, when the light intensity increased and stopped before sunset. Flying from perches to ground, walking and wing flapping were very usual in morning sunlight. Prakash et al. (2012) reported that generally they did not attempt to fly until the day warms up.

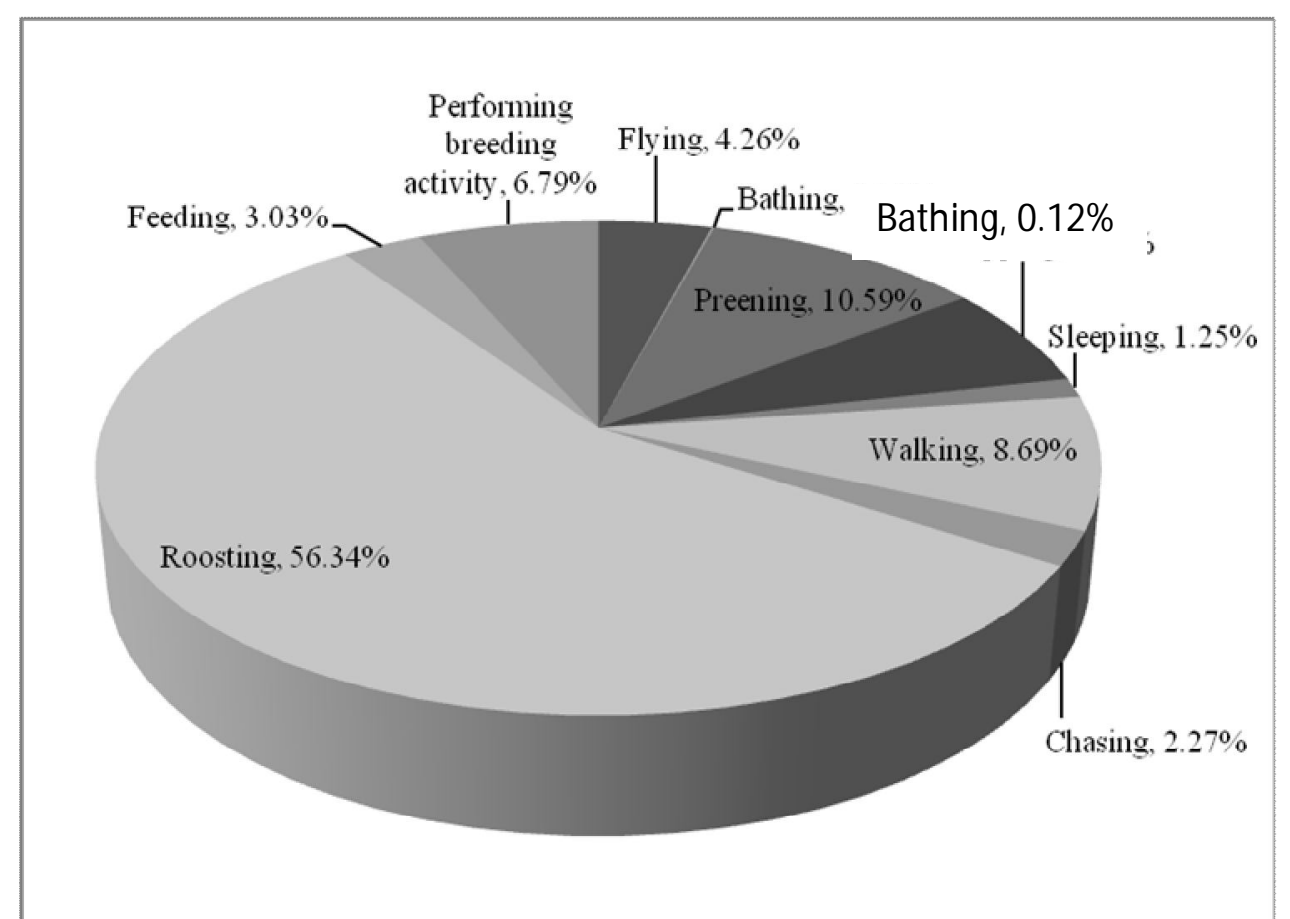

Fig.1. Percentage of time spent in different activities by white-rumped vulture in captivity at Bangladesh National Zoo, Dhaka

There are many factors that affect activity patterns of animals such as climatic difference, cycles of light and dark, phases of the moon, biological cycles, temperature cycles, regular feeding bouts and predation risk (Lehndal, 2008; Kamler et al., 2007). The activity budget is mainly constrained by digestion time rather than searching time (Owensmith \& Novellie, 1982; Belovsky, 1978). In the present study, we observed that whiterumped vulture remained inactive (i.e., roosting and sleeping) over half $(57.59 \%)$ of its time of activity budget in captivity. The finding is supported by Lehndal (2008), who reported most animals divide their time into two fundamentally different behavioral states: activity and rest. Moreover, in captivity food is available during the course of the day and there is no predator pressure thus spend most of their time in resting; and Prakash et al. (2012) noted due to their large size, vultures need to conserve energy and avoid demanding activities. Like the largest carnivores, Gyps vultures conserve energy by remaining inactive whilst digesting their relatively large meal. Neck dropping posture was sighted during sleeping. Feeding activity was related to food supply by the Zoo authority. Vultures were observed to take small amount of fresh supplied food and avoided taking 
stale food. Sometimes, they did not take any supplied food in the whole day. In healthy vultures sufficient food can be taken into the crop at one meal to last several days (Prokash et al., 2012). They spent only 3.03\%, $(\mathrm{n}=145)$ of its active time in feeding. Paired dominant vulture chased away the others just after food supply. Birds chase and bite one another during food taking (Prakash et al., 2012). The highest feeding activity $(n=68)$ was recorded in January. Usually, during breeding season female takes extra food and the majority of breeding activities were recorded between November and January.

The study was also aimed to investigate the breeding success of white-rumped vulture in captivity at Bangladesh National Zoo, Dhaka. White-rumped vulture bred from October to April (Baral et al., 2005); therefore, observation was carried out during the breeding season. The majority of breeding activities $(n=294)$ were recorded from November to January. The vultures were sighted on sitting and roosting $(n=88)$ together which was the probable sign of courtship displays (Prakash et al., 2012). The pair was also involved in nest building activities and observed to collect branches of tree from the ground and rearranged nesting materials. The paired vulture were observed in copulation $(n=16)$. During mating male bit on the neck of female and the female produced harsh sound. Most Gyps vultures generally make a low creaking/grating/hissing type of noise during copulation (Prokash et al., 2012). The paired vultures used to sit $(\mathrm{n}=40)$ in the artificial nest. Sometimes displaced other by bite to take over the nest. During the observation period, we did not record any egg. Further intensive study could find the exact reason of failure of egg laying subsequently breeding success of white-rumped vulture at Bangladesh National Zoo, Dhaka.

Agonistic interactions were also noticed, although white-rumped vulture lives in group peacefully. The paired individual chased away $(n=109)$ by biting with harsh sound or expanding the wings move forward if any other individual approached to interact breeding pair. Sometimes, their forelimbs were also used to flee away others. One individual was observed with injured neck. Vultures can be susceptible to disturbance during the breeding season and can injure themselves in enclosures if disturbance is not kept to a reasonable, manageable (Prakash et al., 2012). White-rumped vultures did not get scared of human presence and remained undisturbed during the study period. The present study can be useful for understanding the behavioral activitics of white-rumped vulture which may provide more appropriate management practice both in wild and captivity. We suggest more intensive studies (such as, comparison of behavioral patterns between captive and wild population) are greatly needed to provide a sound basis for understanding the activity patterns of the species or proper captive management of zoo animals.

\section{REFERENCES}

Altmann, J. 1974. Observation study of behavior: sampling methods. Behav, 49: 227-267.

Ahammed, R., Aktar, M., Khan, M.M.H. and Kabir, M.M. 2013. Activity pattern, feeding and social behavior of barking deer Muntiacus muntjak (Zimmermann, 1780) in captivity. Jahangirnagar Univ. J. Biol. Sci., 2(2): 51-58. 
Ahmad, N.1968. An Economic Geography of East Pakistan. Oxford University Press, London. pp. 56.

Baral, N., Gautam, R. and Tamang, B. 2005. Population status and breeding ecology of whiterumped vulture Gyps bengalensis in rampur valley, nepal. Forktail 21: 87-91

Belovsky, G.E. 1978. Diet optimization in a generalist behaviour: the moose. Theor Popul Biol, 14: $105-134$.

Gilbert, M., Watson, R.T., Virani, M.Z., Oaks, J.L. and Ahmed, S. 2006. Rapid population declines and mortality clusters in three Oriental White-backed vulture Gyps bengalensis colonies in Pakistan due to diclofenac poisoning. Oryx 40: 388-399.

Gunawan, 2005. Daily behaviour development of captive White-bellied Sea Eagles Haliaeetus leucogaster (Gmelin, 1788) in Jogja Animal Rescue Centre, Indonesia. P. 228 In Abu, J., Chong, M.H.N., Sebastian, A.C. and Aik, Y.C. (eds.), Proceedings of the 4th Symposium on Asian Raptors 2005. Committee for the 4th Symposium on Asian Raptors 2005, Kuala Lumpus, Malaysia.

ISARPW, 2004. Report on the international South Asian recovery plan workshop. Buceros 9: $1-48$.

IUCN, 2012. IUCN Red List of threatened species. http://www.iucn.org.

IUCN, 2014. IUCN Red List of Threatened species. http://www.iucn.org.

Kamler, J. F., Jxdrzejewska, B. and Jxdrzejewski, W. 2007. Activity patterns of red deer in Bialowieza National Park, Poland. Journal of Mammalogy, 88 (2): 508- 514.

Khan, M.M.H. 2013. Population, breeding and threats to the white-rumped vulture Gyps bengalensis in Bangladesh. FORKTAIL 29 (2013): 52-56

Lehndal, L. 2008. Activity patterns, diurnal and nocturnal behaviour of the marsh deer Blastocerus dichotomus in the Jatai Ecological Station, Brazil. Student report. Swedish University of Agricultural Sciences.

Martin, P. and Bateson, P. 1993. Measuring Behaviour: An Introductory Guide, (2 ${ }^{\text {nd }}$ Ed.). Cambridge University Press, Cambridge, U. K.

MOEF, 2006. Proceedings of the International Conference on Vulture Conservation. Ministry of Environment and Forests, Government of India, New Delhi.

Owen-Smith, N. and Novellie, P. 1982. What should a cleaver ungulate eat? Am Nat 119: 151-178.

Prakash, V., Green, R.E., Pain, D.J., Ranade, S.P. and Saravanan, S. 2007. Recent changes in populations of resident Gyps vultures in India. J. Bombay Nat. Hist. Soc. 104: 129-135.

Prakash, V., Bowden, C., Cuthbert, R., Lindsay, N., Prakash, N., Routh, A. and Parry-Jones, J. 2012. Husbandry Guidelines for 'in range' conservation breeding programmes of Gyps bengalensis, Gyps indicus and Gyps tenuirostris. Version 1.0 pp, 54. Royal Society for Protection of Birds, Sandy, UK: ISBN - 978-1-905601-34-9.

Relyea, R.A., Ortega, I.M. and Demarais, S. 1994. Activity monitoring in mule deer: Assessing telemetry accuracy. Wildl. Soc. Bull, 22: 656-661.

SAVE, 2014. A blueprint for the recovery of South Asia's Critically Endangered Gyps Vultures. pp.5. http://www.save-vultures.org/

Swan, G., Naidoo, V., Cuthbert, R., Green, R.E., Pain, D.J., Swarup, D., Prakash, V., Taggart, M., Bekker, L., Das, D., Diekmann, J., Diekmann, M., Killian, E., Meharg, A., Patra, R.C., Saini, M. and Wolter, K. 2006. "Removing the threat of diclofenac to critically endangered Asian vultures". PLoS Biology 4(3): 396-402. 